\title{
OS CENTROS LOGÍSTICOS E INDUSTRIAIS ADUANEIROS E A INTEGRAÇÃO TERRITORIAL NO ESTADO DE SÃO PAULO
}

\author{
Lucas Ferreira Rosa Penha*
}

\begin{abstract}
RESUMO:
De agosto a dezembro de 2006 esteve em vigência uma medida provisória que alterava os procedimentos de criação de estações aduaneiras em zona secundária (portos secos) e criava, assim, uma nova categoria de recinto aduaneiro: o Centro Logístico e Industrial Aduaneiro (CLIA). São armazéns alfandegados onde se realizam os procedimentos de desembaraço aduaneiro na importação e exportação de mercadorias, entretanto, não estão localizados nas zonas de portos e aeroportos (zona primária). A medida estabeleu uma "liberalização" do setor ao transferir a iniciativa da criação destes recintos à esfera privada quando até então era de encargo exclusivo da Receita Federal, por meio de processos licitatórios. Trata-se de objetos geográficos com densidades técnicas e normativas que firmam-se como alternativa aos portos e aeroportos para os procedimentos de desembaraço aduaneiro. O presente trabalho pretende entender as implicações territoriais destas novas estruturas no estado de São Paulo, em um período caracterizado pela dispersão e dissolução do processo produtivo e pela crescente importância da circulação dentro deste.
\end{abstract}

PALAVRAS-CHAVE:

Fluidez territorial - porosidade territorial - logística - circuitos espaciais produtivos - aduanas

\section{ABSTRACT:}

From August to December 2006, a provisional executive order has changed the procedures for setting up customs stations in the secondary zones (dry-ports) and created thereby a new category of customs enclosure: Custom Logistics and Industrial Centers (CLIA). They are bonded warehouses (located out of the primary zones, wich are airports and ports areas) where import and export procedures are performed. The provisional executive order established a "liberalization" of the sector by transferring the initiative of establishing such grounds to the private sphere. Before that, it was a government responsability, through bidding process. They are geographical objects with technical and normative "densities" chosen as an alternative way to the procedures of customs clearance. This paper aims to understand the territorial implications of these new structures in the State of São Paulo, in a period characterized by the dispersion and dissolution of the production process and the increasing importance of its circulation.

\section{KEY-WORDS:}

Territorial fluidity - territorial porosity - logistics - productive space circuits - customs 


\section{Introdução}

O presente trabalho é uma tentativa de apresentação do tema dos Centros Logísticos e Industriais Aduaneiros (CLIAs) e suas implicações territoriais no Estado de São Paulo a partir de uma perspectiva geográfica. Os CLIAs são recintos alfandegados em zona secundária, criados para a facilitação dos procedimentos de importação e exportação, apresentando-se como alternativas aos portos e aeroportos. Para a tarefa de apresentá-los, é necessária a compreensão das razões de sua criação (projeto político) e das lógicas de seu funcionamento, identificando os principais atores sociais envolvidos diretamente no projeto e aqueles mobilizados de maneira indireta. Nosso objetivo é o de realizar tal análise de modo a articular operacionalmente teoria e conceitos caros à ciência geográfica com o recorte da realidade concreta selecionado. Assim, mais um tema de fundamental importância para a compreensão das transformações pelas quais passa o território nacional no atual período do desenvolvimento capitalista mundial será posto dentro de uma abordagem que atrela, dialeticamente, fenômenos sociais aos seus condicionantes e produtos espaciais, na qual o território, no seu uso, representa uma totalidade em contínuo processo de mutação (SANTOS, 1994).

O tema é um vasto campo a ser explorado pelo pensamento geográfico já que toca a fundo em debates como a dinâmica dos fluxos no território, a híbrida regulação do território travada entre o público e o privado, e a competitividade que tais recintos, como componentes de um sistema logístico, imprimem ao território. Quando enxergamos os CLIAs como objetos geográficos construídos técnica e normativamente e, portanto, elementos constitutivos do território nacional, uma análise geográfica pode ser realizada. Quando nos debruçamos sobre as minúcias de suas composições técnicas e normativas, somos remetidos, automaticamente, às análises das escalas local, regional, nacional e mundial, revelando a importância desses recintos dentro de diversos circuitos espaciais produtivos. Estes, na atual fase do capitalismo mundial, se dispersam pelas diversas regiões do mundo e se mantêm conectados por meio do avançado estado das técnicas de transportes e comunicações. Assim, o entendimento da existência dos CLIAs passa, obrigatoriamente, pela compreensão da lógica mundial de acumulação capitalista e suas implicações específicas em território nacional.

Os CLIAs desempenham importante papel na circulação das mercadorias, etapa do circuito produtivo cada vez mais relevante para as estratégias produtivas das empresas. Sendo eles recintos alfandegados, tal papel é exclusivo para a circulação das mercadorias em fluxos de entrada ou saída do país, portanto, para empresas com circuitos espaciais produtivos que contemplam importação ou exportação. O aprofundamento da divisão internacional do trabalho, principalmente a partir da transição do capitalismo fordista para a produção flexível (HARVEY, 2004), na década de 1970, impôs à circulação - material e imaterial - papel decisivo nas políticas de empresas e Estados para a inserção de produtos nos mercados internacionais cada vez mais competitivos. Essa lógica já caracterizava o período técnicocientífico e informacional e começava a construir seu correspondente meio geográfico, de mesmo nome (SANTOS, 2002).

A intensificação desse processo em território nacional deu-se nos anos $1990 \mathrm{com}$ uma abertura dos mercados nacionais nunca antes sentida, sustentada por políticas neoliberais que aumentaram consideravelmente o número de empresas multinacionais presentes no Brasil e seus respectivos fluxos comerciais (mercadorias e dinheiro) internacionais ${ }^{1}$. Este é o período em que encontramos os principais embriões dos CLIAs: interesse pelo aumento da velocidade nos fluxos e pela qualificação dos serviços associados a eles. Logicamente, esses interesses sempre existiram em produções do tipo capitalista, mas nesses últimos anos do século passado ganharam importância tão acentuada que se tornaram decisivos na 
competitividade dos produtos nos mercados internacionais, caracterizando o atual período de globalização.

\section{Os CLIAs como manifestação territorial do atual período}

Para esclarecer nosso ponto de partida ao entendimento dos Centros Logísticos e Industriais Aduaneiros e de suas implicações nos lugares onde são instalados é necessário expressarmos nossos referenciais teóricos sobre os quais embasaremos nossa análise. O fenômeno estudado está geneticamente vinculado, e não poderia deixar de ser, ao movimento da história, que já passou a ser mundial, senão no século XVI com as grandes navegações, nos seguintes com o aprofundamento da divisão internacional do trabalho trazido pelo modo de produção capitalista. Portanto, não está apenas inserido em um contexto temporal, mas é por ele condicionado e produzido, não restando-nos outra alternativa que a compreensão do dito contexto. Entendemos que a caracterização do espaço geográfico no pósguerra através do conceito de meio técnicocientífico e informacional, colocado por Milton SANTOS (2002), coincide com a concretude e funcionamento do mundo no período referido. Só então pudemos viver um mercado global, viabilizado pela imbricação de técnica e ciência, e pelo aproveitamento que dela fizeram as grandes empresas, distinguindo o período de seu precedente.

Do mesmo fenômeno está falando David HARVEY (2004) quando explica que a década de 1970 representa uma ruptura de modelos produtivos. A informação ganha importância chave no novo modelo intitulado "produção flexível", tida como a solução para o esgotamento das possibilidades do modelo fordista de produção. "Novas técnicas e novas formas organizacionais de produção puseram em risco os negócios de organização tradicional" (p. 146), fazendo com que novas estratégias começassem a ser buscadas pelas empresas no sentido de adequação às exigências dos novos mercados. A dissolução do processo produtivo em unidades setoriais e geograficamente dispersas teve, nesse período, sua maior expressão, produzindo uma mais complexa e profunda divisão territorial do trabalho. E é o desenvolvimento técnico, fruto também das novas pesquisas científicas, que possibilitou a coordenação e a realização das produções nessa nova fase. Comunicações e transportes foram as áreas responsáveis por essa viabilização.

Claude RAFFESTIN (1993) entende a comunicação e a circulação como expressões das redes geográficas. A primeira, imaterial e estratégica - já que não pode ser vista representada por fluxos de ordens, dinheiro, informações, e a segunda, material e sempre visível, como pessoas e mercadorias. As redes geográficas, união destas duas variáveis, começam a sobressair-se dentro do processo produtivo capitalista. Em um período em que empresas e suas mais especializadas unidades buscam os lugares mais atrativos para a rentabilidade de suas atividades num espaço amostral que coincide com o mundo, a coordenação e realização da produção são fatores fundamentais na política de crescimento das empresas e se traduzem em comunicação e circulação viabilizados por redes geográficas impregnadas de técnica e ciência.

Frente a essa nova organização da produção em escala mundial, iniciada no pósguerra e reafirmada após a década de 1970, Milton Santos e María Laura Silveira (2001) propõem conceitos para operacionalizar as análises contemporâneas que se deparam com a ideia de divisão territorial do trabalho. Segundo os autores, a divisão territorial do trabalho é instrumento fundamental para a identificação da "repartição das atividades entre lugares" (p. 143), mas o funcionamento dessa produção repartida é apreendido através de um par de conceitos que captam o movimento do processo, fugindo do estático quadro da divisão territorial do trabalho. Circuitos espaciais produtivos e círculos de cooperação no espaço são, então, ferramentas úteis a nós para a apreensão do movimento intrínseco e cada vez mais importante do processo produtivo capitalista nos dias de hoje. Os CLIAs 
desempenham uma clara função no circuito espacial produtivo de inúmeros produtos. Por serem recintos alfandegados destinados ao controle fiscal e administrativo de mercadorias de comércio exterior, entram no circuito da produção como etapa da distribuição (transporte).

O aprofundamento da divisão territorial do trabalho, fazendo dispersar as atividades produtivas pelo mundo, cria uma infinidade de unidades produtivas especializadas, uma infinidade de empresas prestadoras de serviços e uma infinidade de meios de comunicação e de transportes, isto é, as relações tornam-se mais complexas e os contextos alargam-se. Ao contrário do que se possa pensar, tudo isso contribui para uma racionalidade econômica cada vez mais presente, na medida em que as unidades produtivas aumentam sua produtividade, os serviços especializam-se e os meios de comunicação e transportes possibilitam o aumento da velocidade dos fluxos. Roberto Lobato CORRÊA (1997) contribui com mais um conceito para o debate. Para ele, "as diferenças de lugares face às necessidades historicamente identificadas" (p. 280) criam as interações espaciais, representantes das transformações sociais e reprodutoras das desigualdades existentes. Ainda de acordo com o autor, a Revolução Industrial imprimiu à sociedade transformações que se expressaram através da modificação das interações espaciais, como o aumento das trocas e "dos meios de circulação e comunicação" (p. 281), ampliação das redes geográficas e aumento da velocidade dos fluxos, anunciando a superação do espaço pelo tempo. Essas transformações se intensificaram na segunda metade do século $X X$ e, sobretudo, na década de 1990 para os países periféricos de capitalismo tardio.

Entendendo os CLIAs como objetos geográficos produzidos pelo período técnicocientífico e informacional - chamado de globalização (SANTOS, 2001) ou mundialização (CHESNAIS, 1996) - pretendemos associar seu nascimento à ultima década do século passado. É somente nesses anos que a periferia do mundo capitalista conhece a conciliação das condições técnicas e políticas que viabilizam a intensificação dos fluxos internacionais nesses territórios. A unicidade técnica da qual Milton Santos (2001) fala é possibilitada pela técnica da informação, que congrega todas as outras técnicas de forma hegemônica e pode, então, se fazer sentir instantaneamente no mundo todo. Associando essa possibilidade técnica às políticas de liberalização, privatizações e desregulamentações adotadas pelos governos Thatcher e Reagan, na década de 1980 - e expandidas para a América Latina nos anos 1990 - que podem ser consideradas condicionantes políticas para a desenfreada expansão dos grupos multinacionais (CHESNAIS, 1996), o período mais recente da história capitalista mundial pôde se realizar em território brasileiro. Logo, a importância dada à circulação, mesmo existente já desde outros períodos capitalistas, torna-se maior nesta fase recente, exigindo de Estados e empresas velocidade na movimentação dos fluxos.

Não é sem motivos que a expressão "imperativos da globalização" aparece em análises que buscam decifrar o atual período histórico. As características do meio técnico-científico e informacional e o seu uso nos revelam que a sobrevivência das grandes empresas - aquelas que organizam sua produção em escala planetária - depende, dentre outros fatores, da rapidez com que coloca sua produção à disposição do mercado. María Laura Silveira (2003) explica que os Estados inventam uma viabilidade para os territórios. Em outras palavras, adaptam seus territórios às exigências das grandes empresas. Estas buscam no território, usado como recurso, fatores que transfiram competitividade aos seus produtos no mercado global. Os CLIAs são densidades técnicas e normativas que se encaixam nessa viabilização do território.

\section{Entendendo os CLIAs}

Os CLIAs são uma nova categoria de aduana, criada com a medida provisória n 320 , de 24 de agosto de 2006, que teve vigência de apenas seis meses, mas durou o suficiente para licenciar cinco recintos. A medida estipulava que 
empresas interessadas em prestar os serviços públicos de armazenagem e movimentação de mercadorias importadas e daquelas destinadas à exportação poderiam obter a correspondente licença da Receita Federal mediante preenchimento dos requisitos técnicos, financeiros e operacionais legalmente especificados. Tratouse de procedimento diferente daquele existente até então, que consistia na licitação pública como único modo de criação das aduanas interiores, conhecidas como portos secos. Essencialmente, a nova medida alterou o quadro jurídico de criação de novos recintos alfandegados na zona secundária ${ }^{2}$ ao fazer migrar à iniciativa privada o interesse e a possibilidade do alfandegamento, quando eles eram de competência do governo federal. De acordo com o documento de Exposição de Motivos $^{3}$ da medida provisória, o risco de comprometimento da oferta de serviços aduaneiros era justificativa para essa "liberalização" do setor.

No Brasil, todo procedimento de importação ou exportação de produtos deve passar, obrigatoriamente, por uma aduana para que somente então eles possam seguir para os lugares de destino - dentro do Brasil (importações) ou exterior (exportações). A aduana é uma área alfandegada, isto é, com limites físicos estabelecidos pela Receita Federal dentro dos quais são autorizados os serviços de controle e fiscalização - despacho aduaneiro ${ }^{4}$ das mercadorias importadas e daquelas a serem exportadas - sempre realizados pela Receita Federal. O território nacional pode ser dividido em zona primária - aquela de contato limítrofe entre o espaço econômico nacional e aquele internacional - (portos, aeroportos e postos de fronteira), na qual é realizada a maior parte dos procedimentos aduaneiros de importação e exportação, e zona secundária - o restante do território - onde, atualmente, existem alguns tipos de recintos alfandegados, como portos secos, terminais alfandegados privativos e Centros Logísticos e Industriais Aduaneiros.

Os CLIAs são empresas que dispõem de um conjunto de áreas alfandegadas (na forma de armazéns ou pátios) com a presença de um posto da Receita Federal, autorizadas a realizar atividades aduaneiras e tornam-se, então, uma opção para importadores e exportadores delegarem o tratamento aduaneiro de suas mercadorias. Podem ser uma opção atrativa para algumas empresas por oferecerem maior especialização nos serviços aplicados à mercadoria (gerenciamento de estoques, habilitação para tratamento de tipos específicos de produtos, rapidez e segurança nos procedimentos) em confronto com os portos e aeroportos que têm outras funções, além destas, para desempenhar, como carga e descarga de mercadorias e sua movimentação.

Adiantamos, aqui, a importância da Região Metropolitana de São Paulo para o funcionamento dos CLIAs. De acordo com trabalho realizado por Mónica ARROYO (2004), o estado de São Paulo participa com cerca de $40 \%$ de todo o comércio exterior brasileiro, sendo a RMSP aquela com quase metade das exportações e importações do estado. Isso é reflexo da "convivência de uma multiplicidade de empresas exportadoras" (p. 93) na RMSP, que aumenta sua espessura, isto é, a complexidade de seu sistema de fluxos. Estão nessa área as principais demandas pelos serviços aduaneiros de um CLIA.

A opção por utilizar o CLIA como recinto alfandegado gera, no transporte da mercadoria, uma escala adicional, exigindo dele a oferta de atrativos que compensem esse fator antieconômico. Como mostra o fluxograma a seguir, o caminho da mercadoria importada ou exportada se torna mais longo quando esta passa pelo CLIA. Nas exportações, a mercadoria deixa a empresa exportadora sendo transportada até o CLIA, que realizará todas as operações aduaneiras necessárias para a exportação. Do CLIA, a mercadoria é transportada - já despachada e, portanto, sob regime de trânsito aduaneiro ${ }^{5}$ - até um ponto da zona primária, caso deva ser exportada por via aérea (aeroporto) ou marítima (porto), onde será diretamente carregada para exportação. Nos procedimentos de importação, a mercadoria chega pela zona primária e desta parte diretamente para o CLIA, sob regime de 
trânsito aduaneiro porque não foi ainda nacionalizada. Apenas quando chega ao CLIA será sujeita aos serviços de conferência e controle aduaneiros e, somente após cumprida esta etapa, poderá ser transportada à empresa importadora.

\section{Fluxo da mercadoria - importação e exportação}

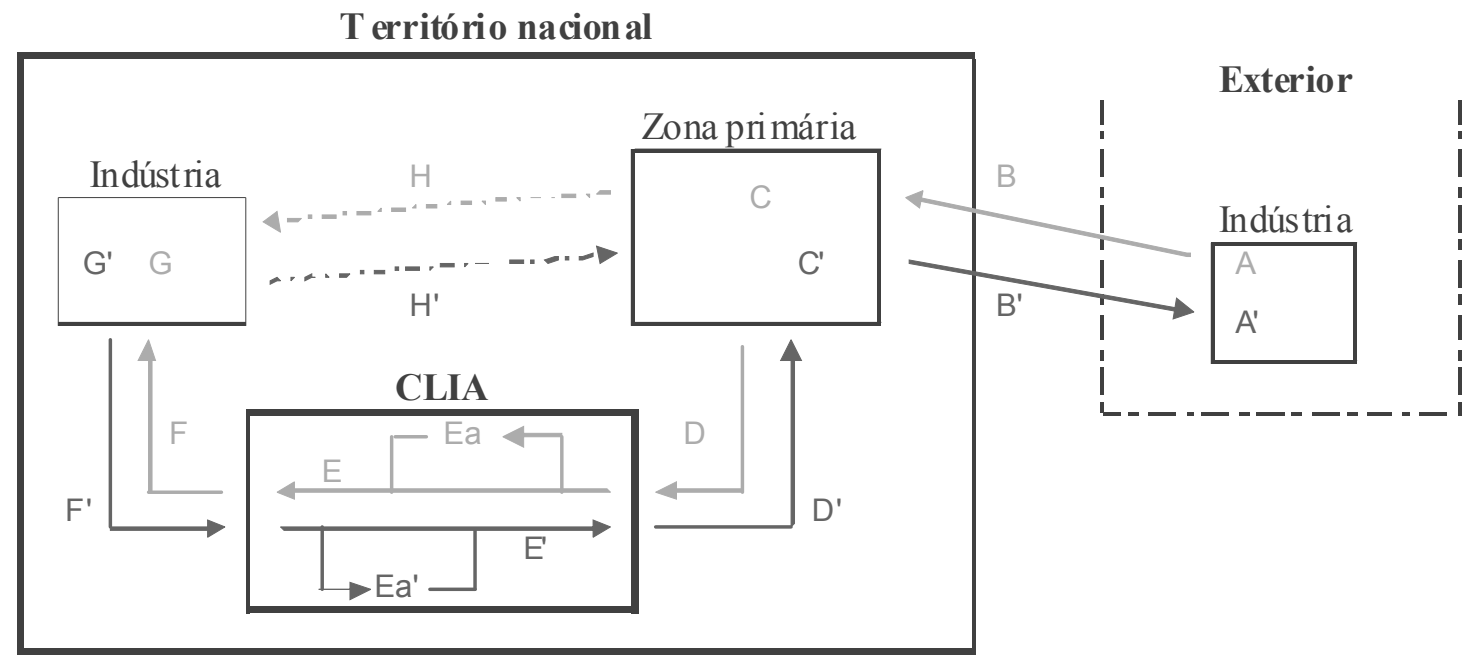

Legenda:

Importação

A - Saída da mercadoria no exportador (exterior).

B - Transporte em área internacional.

C - Chegada em território nacional / Desembarque.

D - Transferência para o CLIA sob regime de Trânsito Aduaneiro.

Ea - Armazenagem da mercadoria ainda não nacionalizada.

E - Nacionalização / pagamento de tributos / liberação da carga.

F - Transporte da mercadoria liberada ao importador.

G - Chegada da mercadoria no importador.

H - Fluxo da mercadoria em caso de não utilização do CLIA*.
G' - Saída da mercadoria no exportador.

$\mathbf{F}^{\prime}$ - Transporte em território nacional até o CLIA.

Ea' - Armazenagem da mercadoria ainda não despachada.

E' - Despacho aduaneiro / pagamento de tributos / lacre.

D' - Transferência da mercadoria despachada à zona primária sob regime de Trânsito Aduaneiro.

$\mathbf{C}^{\prime}$ - Embarque direto.

B' - Saída do território nacional.

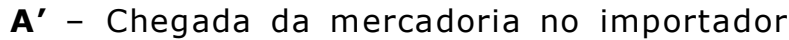
(exterior).

H' - Fluxo da mercadoria em caso de não utilização do CLIA*.

* Nesses casos, os procedimentos indicados por E e $\mathbf{E}^{\prime}$ são realizados na zona primária. 
É importante destacar a principal modalidade de importação e exportação realizada pelos CLIAs, já que são muitos os regimes oferecidos por esses recintos. O regime especial de entreposto aduaneiro ${ }^{6}$ é o mais demandado, já que permite, tanto na importação quanto na exportação, a suspensão dos impostos enquanto a mercadoria não é nacionalizada ou despachada. Os impostos só incidem sobre a fração da mercadoria nacionalizada ou despachada e devem ser pagos apenas depois deste procedimento. Para o importador ou o exportador, esse regime é interessante porque permite o armazenamento da mercadoria sem a obrigação do pagamento imediato dos impostos, que é realizado apenas quando os serviços aduaneiros são prestados (coincidindo com a demanda do consumo das mercadorias estocadas).

Outro regime aduaneiro possível de ser oferecido pelos CLIAs é o de entreposto industrial ${ }^{7}$, que consiste na possibilidade de realização de pequenos processos de caráter industrial (etiquetagem, marcação, testes de funcionamento, acondicionamento e reacondicionamento, montagem e beneficiamento) por meio da instalação de filiais de indústrias na área alfandegada, com aprovação da Receita Federal. A ideia é a de incentivar as exportações pelas vantagens tributárias da importação de matériasprimas necessárias à composição do produto final a ser exportado. Entretanto, a burocracia envolvida nas aberturas de filiais dificulta o aproveitamento desse regime e, hoje, esses procedimentos contemplam parcela insignificante dos serviços prestados.

\section{Como e por que foram criados}

A criação do CLIA como categoria de recinto alfandegado não pode ser entendida como resultado de um fator isolado ou casual, mas sim como um conjunto de fatos e fatores articulados durante ao menos uma década que foram apropriados por sujeitos sociais para a produção de um projeto de lei e sua conseguinte aprovação. Mesmo tendo sido arquivada meses depois, a medida provisória que cria legalmente o CLIA nada mais é do que o resultado último de um longo e complexo processo de debates políticos e confrontos de interesses (públicos e privados), travados em reuniões, conferências e associações representativas das empresas do setor, num primeiro momento, e no Congresso Nacional, em fase posterior. Logo, o texto da Lei, como em qualquer outro caso, exprime em poucas linhas o árduo processo político desenrolado a priori. Tentaremos identificar, a seguir, a trama dos acontecimentos e dos sujeitos envolvidos que antecipou a regulamentação dos CLIAs.

Até $1996^{\circ}$, quando os portos secos foram instituídos sob o nome de Estações Aduaneiras do Interior, as importações e exportações eram realizadas exclusivamente na zona primária portos, aeroportos e postos de fronteira - ou em terminais retroportuários alfandegados. Com a criação dos portos secos, a partir da segunda metade da década de 1990, parte significativa das mercadorias de comércio exterior passou a ser controlada e fiscalizada nesses novos recintos de zona secundária que surgiam como via alternativa para empresas prejudicadas pelos lentos e burocráticos procedimentos aduaneiros dos recintos portuários. Os CLIAs surgem ainda neste contexto de criação de alternativas rápidas e eficientes em contraposição à estrutura sobreutilizada dos tradicionais portos e aeroportos, porém, como resultado de uma forte pressão política das empresas de armazéns gerais no sentido de uma maior liberalização desse mercado.

A medida provisória $\mathrm{n}^{\circ} 320^{9}$, aprovada em agosto de 2006, estabelece novos procedimentos para a criação dos recintos alfandegados em zona secundária, denominando-os Centros Logísticos e Industriais Aduaneiros. De acordo com o documento Exposição de Motivos referente à medida provisória, produzido em dezembro de 2005, o objetivo da medida provisória é a "reestruturação do modelo jurídico de organização dos recintos aduaneiros de zona secundária" justificada, também segundo o documento, pela possibilidade de sobrecarga de procedimentos de desembaraço aduaneiro dadas as condições aduaneiras do território brasileiro. Os procedimentos de abertura de portos secos 
estavam sujeitos aos modelos de concessão e permissão, isto é, abertura de licitação pública e concessão do serviço à empresa selecionada. O aumento do número de portos secos em território nacional estava subordinado à iniciativa pública, por meio da Receita Federal, que apenas abria licitação após avaliação da demanda econômica. Esta prática, de acordo com o documento, não estava em consonância com o aumento da movimentação de cargas nos portos e, por isso, não era capaz de "responder prontamente às demandas do mercado", que exigiriam rápidas adequações operacionais e mudanças locacionais. A ideia do CLIA surge fundamentalmente para eliminar esse fator limitante que restringe 0 ingresso de novas empresas no mercado, já que seus serviços - movimentação e armazenagem de mercadorias em processos de importação e exportação - não são considerados de natureza pública pelos idealizadores do projeto.

Com as especificações legais da MP 320, alteram-se os procedimentos para instalação de recintos aduaneiros em zona secundária. De um sistema de concessão passa-se a um sistema de licença. Esta "é o ato administrativo unilateral e vinculado pelo qual a Administração faculta a todos os que preencham os requisitos legais o exercício de determinada atividade" e seu funcionamento seria condizente com os interesses de liberalização do mercado de armazéns alfandegados. Assim, a abertura de um CLIA não depende mais da abertura de licitação por parte da Receita Federal e depende apenas do preenchimento dos requisitos estipulados em lei para a aprovação da licença para exercício dos serviços de CLIA. A medida estabeleceu, então, via livre para a iniciativa privada na criação dos CLIAs e na passagem voluntária dos portos secos ao regime de CLIA.

Atualmente, funcionam, em território nacional, cinco CLIAs. O Grupo Mesquita detém dois recintos, um em Santos e o outro no Guarujá, com licenças outorgadas em 17 de novembro de 2006. Na mesma data, a Deicmar S.A. conseguiu a licença para seu CLIA, também em Santos. O Grupo Colúmbia Armazens Gerais teve sua licença para operar como CLIA em Santos no dia 11 de dezembro de 2006 e a CRAGEA, de Suzano, no último dia de vigência da MP, 14 de dezembro de 2006, teve sua licença aprovada. Todas elas são grandes empresas do setor de armazéns gerais, com reconhecida tradição e longa experiência no ramo, garantindo relevante força política, necessária para a sustentação do projeto em questão.

\section{CLIA: Fluidez e porosidade territoriais}

O caráter híbrido do espaço geográfico (SANTOS, 2002) é evidente em suas formas na medida em que estas revelam, sugerem ou mascaram - dependendo de suas naturezas duas modalidades de conteúdos passíveis de dissociação apenas para fins analíticos, como este. São eles: a técnica e a norma. São, portanto, dois atributos não só do espaço geográfico, mas também, encontrados em cada objeto geográfico que o constitui e o CLIA, como objeto geográfico que é, não deixa de expressar esse hibridismo. Qualquer tentativa de separação entre conteúdo técnico e conteúdo normativo não pode ser, senão um esforço metodológico abstrato para o entendimento da complexidade de nosso objeto de estudo. Sabemos que o espaço geográfico é construído por meio de trabalho humano e, assim, em cada um de seus elementos técnica e norma existem - dialeticamente diluídas e imbricadas - desde o momento de sua criação, isto é, de quando o projeto humano é realizado materialmente.

o conteúdo técnico de um objeto geográfico pode ser identificado a partir de sua composição material, isto é, da cristalização do trabalho dispensado para sua realização. Podemos, aqui, aproximá-lo ao conceito marxista de trabalho morto. Entretanto, não se esgota aí. Toda a possibilidade de ação viabilizada por essa base material e, portanto, capaz de articulá-la em sistema para a satisfação de uma necessidade - e aí encontramos um sistema técnico - soma-se quantitativa e qualitativamente ao seu conteúdo técnico. Resolvemos tratar o CLIA como criador de fluidez territorial (SANTOS E SILVEIRA, 2001) 
sempre que, através de seu conteúdo técnico, tende a tornar fluido o fluxo da mercadoria.

O conteúdo normativo intrínseco aos objetos geográficos é dado pelas funções às quais foram destinados a cumprir e àquelas que, de fato, cumprem. Representa, então, as intencionalidades presentes no projeto e no objeto e estas, por serem informações - conteúdo imaterial - exigem outra estratégia para sua identificação. As normas podem ser formais, quando estipuladas dentro de um quadro jurídico pré-estabelecido, ou não formais, quando existem somente nas práticas sociais, políticas e econômicas. O CLIA, como recinto devidamente regulamentado nos âmbitos jurídicos, está recheado de normas formais, mas também, como qualquer outro objeto geográfico, é, em parte, regido por infinitas normatizações - não formais - estabelecidas pelo seu uso. Enxergamos o CLIA, então, como criador de porosidade territorial (ARROYO, 2001) a partir do momento em que se integra à complexidade do sistema nacional de aduanas e à sua base normativa, aumentando as possibilidades de internacionalização de mercadorias.

A seguir, detalhamos nosso entendimento acerca do CLIA como expressão de fluidez e porosidade territoriais, explicando como seu conteúdo técnico se configura em potenciais de fluidez e, ao mesmo tempo, como seu conteúdo normativo aumenta a porosidade do nosso território.

\section{Procedimentos no CLIA como fluidez territorial (aspecto operacional)}

A fluidez territorial não pode ser considerada como um dado absoluto ou como um atributo do território existente per se, porque estamos lidando com equipamentos de infraestrutura fixados em espaço nacional, isto é, apenas um dos componentes necessários para a realização da mesma (SANTOS, 2001). O outro componente é o próprio fluxo, no nosso caso, da mercadoria que, não existindo, transforma o projeto em capacidade ociosa e o invalida como projeto de desenvolvimento. Portanto, devemos enxergar a fluidez territorial somente nos âmbitos do uso do território (SANTOS, 1994). O território usado nos dá os instrumentos necessários para a relativização dos objetos geográficos e sua contextualização política, social e econômica. A existência dos fixos só pode ser explicada pelo entendimento dos fluxos e estes nada mais são do que a expressão do uso do espaço realizado pelos diferentes sujeitos sociais.

Assim, a fluidez territorial criada pelo conteúdo técnico existente no CLIA é potencial e só passa a ser efetiva quando usada por agentes sociais específicos. A identificação destes é decisiva para o entendimento da importância dos CLIAs nas diversas escalas espaciais, já que indica a parcela da sociedade incluída em cada um destes projetos. Os agentes sociais que utilizam os serviços oferecidos pelos CLIAs - seus clientes - buscam a fluidez e, para isso, gozam de toda a densidade técnica presente nesses recintos, que é bastante diferente daquela encontrada nas estruturas portuárias e aeroportuárias. O fato de CLIAs realizarem operações de despacho aduaneiro, assim como o fazem portos e aeroportos, não implica presença de conteúdos técnicos semelhantes para as duas categorias de recintos. Inclusive, este mesmo fato cria uma concorrência entre zona primária e zona secundária que conduz os CLIAs a uma diferenciação técnica no intuito de atração de clientes. A densidade técnica presente nesses recintos de zona secundária é sensivelmente maior e mais sofisticada do que aquela presente nas tradicionais zonas primárias.

Isso acontece porque, diferentemente dos recintos de zona secundária, os portos e aeroportos são os responsáveis pelo primeiro contato físico na chegada da mercadoria importada e pelo último na saída da mercadoria exportada, caracterizando sua função precípua de carga e descarga (para comércio exterior), exclusiva da zona primária. Os recintos de zona secundária, por não terem de lidar com essa desgastante tarefa, concentram esforços nos serviços de movimentação e armazenamento das mercadorias, especializando-se e aumentando a qualidade destes. Portanto, a diferenciação das 
funções entre zona primária e secundária é o grande motivo para a existência de maiores densidades técnicas no tratamento de mercadorias nos CLIAs.

Organização interna e equipamentos modernos são os principais fatores de superioridade técnica dos CLIAs em relação aos terminais de zona primária. Por essa especialização no tratamento da mercadoria, os CLIAs desenvolveram sistemas de organização de estoque e movimentação de mercadorias atrelados à aquisição de equipamentos (guindastes, empilhadeiras, prateleiras, e pallets) que dotam seus serviços de uma racionalidade importante para a competitividade do mercado. Os equipamentos de controle e fiscalização de mercadorias, como balanças e esteiras, também fazem parte da modernidade técnica do recinto. A divisão interna dos pátios e armazéns revela, também, o grau de especialização no tratamento de certos tipos de mercadorias, como aquelas que necessitam de refrigeração (disponibilidade de geradores de energia ou câmeras frigoríficas) ou aquelas que exigem isolamento e cuidados mais atenciosos (produtos químicos). Sistemas integrados de segurança e vigilância encerram a composição técnica desses recintos.

Esse conjunto de qualidades técnicas aplicado à movimentação e armazenamento das mercadorias é o grande fator compensatório para perda econômica que importadores e exportadores têm ao criarem um elo adicional em seus circuitos espaciais produtivos quando optam pela utilização dos CLIAs. O ganho que as empresas têm com a qualidade dos serviços prestados torna irrisório o transtorno envolvido no desvio do trajeto da carga para o CLIA.

\section{CLIA como poro territorial (aspecto normativo)}

O território brasileiro, como já sugerido em item anterior, também se apresenta como um conjunto indissociável de técnicas e normas, isto é, se constitui por uma base técnica e uma base normativa que condicionam e, ao mesmo tempo, produzem relações sociais, econômicas e políticas
(SANTOS, 1978). Só nestes termos podemos considerar o espaço nacional como uma instância social que regula a sociedade e ao mesmo tempo a expressa. A base normativa, por excelência, é aquela que estabelece explícita ou implicitamente o funcionamento das práticas sociais, econômicas e políticas e é formada pelo conjunto de leis, decretos, acordos, regras, regulamentos normas formais - e de costumes, tradições e solidariedades orgânicas - normas não formais. Entretanto, mesmo a materialidade do território, isto é, sua densidade técnica, torna-se norma quando, por sua durabilidade, induz ações. Encontramos aí, um ponto onde norma e técnica se confundem. As formas são construções materiais que, de diferentes maneiras, favorecem ou dificultam os novos fenômenos e processos a serem criados no espaço, reforçando a ideia do espaço geográfico ativo.

O CLIA apresenta todas essas variantes da base normativa do território, as formais, as não formais e eles como materialidade, porém, sua condição jurídica oficial, isto é, aquela representada pelo seu enquadramento normativo na legislação de Estado, é a mais relevante para o entendimento da essência de sua existência. Como categoria ou modalidade de aduana, contém, na gênese de sua idealização, uma função normativa maior e muito bem definida, que o diferencia do conjunto maior de objetos geográficos. Seu papel alfandegário exige do Estado a produção de um vasto arcabouço de leis e medidas legais para seu funcionamento. Em outras palavras, o fato do CLIA ter a capacidade e a autoridade para receber mercadorias estrangeiras e nacionalizá-las e para receber mercadorias nacionais e despachá-las para o exterior, torna-o de extrema importância para o exercício da soberania nacional e para a reafirmação do Estado-Nação como tal. Por desempenhar serviços de comércio exterior, o CLIA é alvo de legislação específica e estratégica.

Entendendo o território nacional como uma porção do espaço sobre a qual incide um sistema de poder constitucionalmente estabelecido e, por isso mesmo, com fronteiras suficientemente claras que o separam de outros territórios, podemos identificar, como seu 
atributo, uma porosidade territorial (ARROYO, 2001). Ela constitui-se como um sistema de pontos - pequenas áreas - para os quais são direcionados os fluxos internacionais de mercadorias, sendo eles expressos concretamente pelos portos, aeroportos, postos de fronteiras, portos secos, terminais retroportuários alfandegados, CLIAs. Apesar de apresentar-se como uma topologia de recintos alfandegados, a porosidade territorial explica-se mais pela natureza das legislações incidentes em cada um deles e acaba por expressar a capacidade do território em estabelecer trocas comerciais internacionais. Portanto, sua compreensão vai além da análise da dispersão geográfica de seus "poros" e envolve, também, a regulação destes, revelando seus usos.

Pretendemos entender os CLIAs como poros territoriais visto que integram o sistema brasileiro de aduanas e, assim, fazem parte do conjunto de recintos habilitados, e com exclusividade, para realizar as operações de despacho e desembaraço aduaneiros. O Centro Logístico Industrial e Aduaneiro é uma modalidade de recinto, criado em 2006, que representa a mais recente versão de aduana, encerrando (até o momento) uma sucessão de legislações referentes à regulamentação das atividades aduaneiras e, portanto, possui especificações normativas que o diferenciam dos restantes. É importante, então, reafirmar a importância de seu conteúdo normativo, que o estabelece como ponto do território com função político-econômica específica: locus da nacionalização e internacionalização de mercadorias.

\section{A lógica da localização}

Por serem resultado de uma medida provisória que teve vigência de aproximadamente seis meses - da data de sua publicação (agosto de 2006) à data de seu arquivamento (dezembro de 2006) - os CLIAs existentes não apresentam estratégias comuns de localização. Mesmo porque todos eles tornaram-se CLIAs por meio da transformação das concessões de seus portos secos em regimes permanentes de CLIA. Não há nenhum CLIA criado através do processo de outorga de licença a um armazém projetado para tal fim. Em outras palavras, a pouca duração da MP não deixou tempo para o surgimento de novos CLIAs pela demanda do mercado, como previa o texto da lei, impossibilitando a consolidação de um padrão específico de localização.

Entretanto, sendo eles projetos derivados dos portos secos, suas estratégias locacionais coincidiriam com aquelas dos portos secos. Podemos afirmar isso porque o procedimento de instalação de um porto seco dependia da abertura de licitação pela Receita Federal, e esta, baseavase no critério da demanda pelos serviços aduaneiros. O que mudava com os CLIAs era que essa demanda não era avaliada pela Receita Federal, mas pela própria iniciativa privada, que pediria à primeira licença de alfandegamento. Assim, estamos falando sempre da demanda pelos serviços aduaneiros como critérios de localização de portos secos e CLIAs.

De acordo com trabalho realizado por Rafael Pacchiega (2009) existem no Brasil 62 portos secos, sendo que quase metade deles se localiza no estado de São Paulo. O mapa a seguir, retirado do mesmo trabalho, indica essas localizações e inclui os cinco CLIAs existentes hoje.

De acordo com trabalho realizado anteriormente, em referência à Região Concentrada, "explica-se a concentração de portos secos nessa área, pois a região (Sul e Sudeste), recebendo historicamente os vetores de modernização, torna-se, hoje, meio técnicocientífico e informacional" (PENHA, 2005: 27), isto é, espaço de densidades técnicas e políticas funcionais às atuações de grandes empresas do circuito superior da economia (SANTOS, 1979). É nessas áreas que existe a demanda pelos serviços aduaneiros dos portos secos. Segundo Pacchiega (2009), a presença desses recintos em lugares mais afastados da região concentrada explica-se pela formação de lobbys por políticos e empresários regionais para a abertura de licitações em suas áreas de atuação. Nota-se, também, um papel importante do aglomerado metropolitano ${ }^{10}$ de São Paulo no abrigo dos portos 


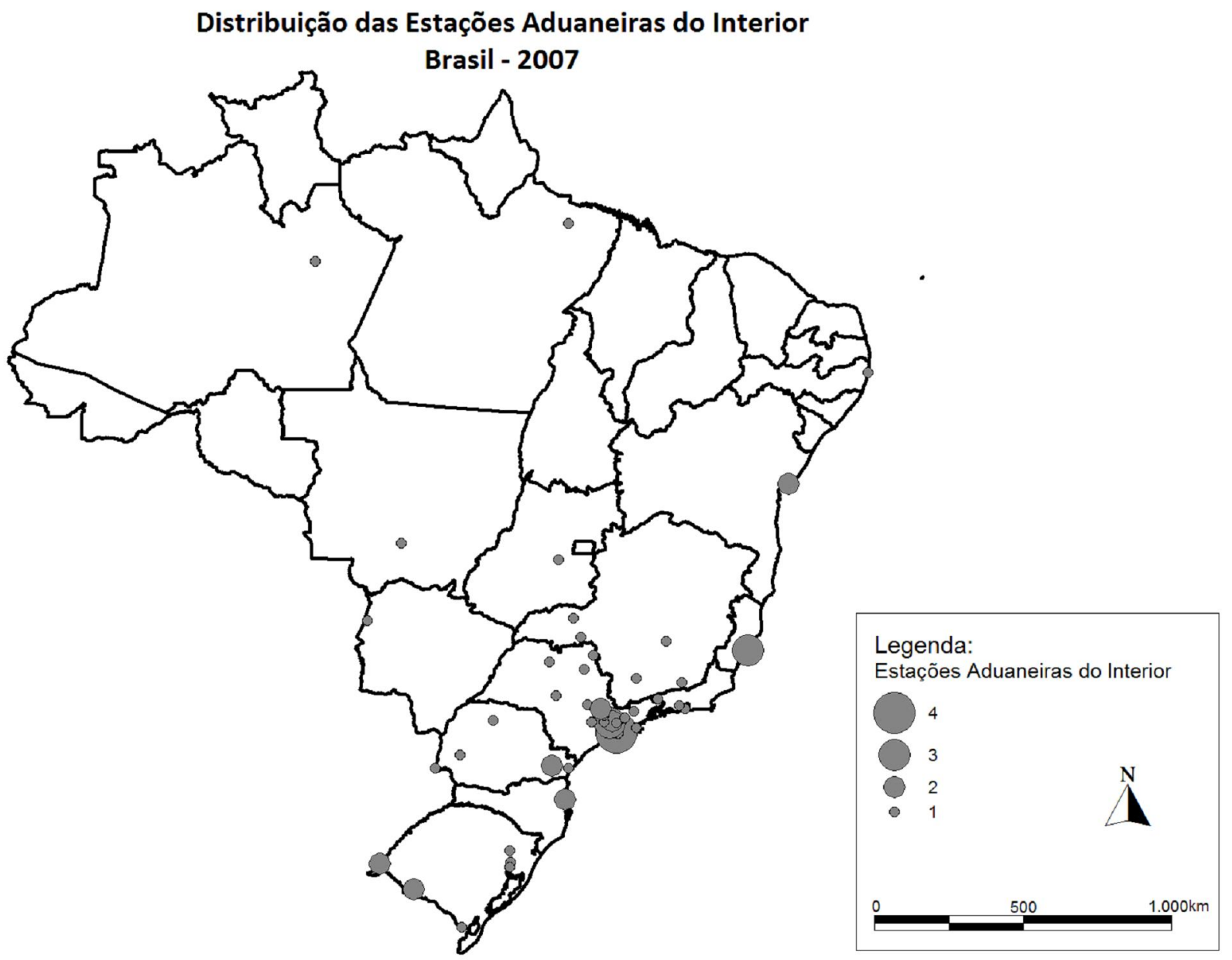

Fonte: PACCHIEGA, 2009

secos, sugerindo exatamente a presença de circuitos espaciais produtivos vinculados ao comércio internacional nessa área.

O objeto de estudo do presente trabalho, isto é, os cinco Centros Logísticos Industriais e Aduaneiros presentes no estado de São Paulo constituem situação de mais complexa análise. $\mathrm{O}$ fato de todos eles atuarem anteriormente como portos secos desloca as razões locacionais para período anterior ao da atuação como CLIAs, fazendo com que a análise do mapa dos CLIAs no estado de São Paulo deva ser realizada com muita cautela. Dado mais interessante é que todos eles são armazéns controlados por grandes grupos empresariais do setor de armazéns gerais. Grupos de antiga tradição que acumularam experiência nas áreas de transporte, armazenamento, despacho aduaneiro e logística integrada, isto é, representam grandes capitais e a maior parte de suas atividades está ligada ao circuito superior da economia, já que o comércio exterior exige das empresas grande quantidade de capital e mercados expandidos, característicos 


\section{OS CLIAS NO ESTADO de SÃo PAULO}

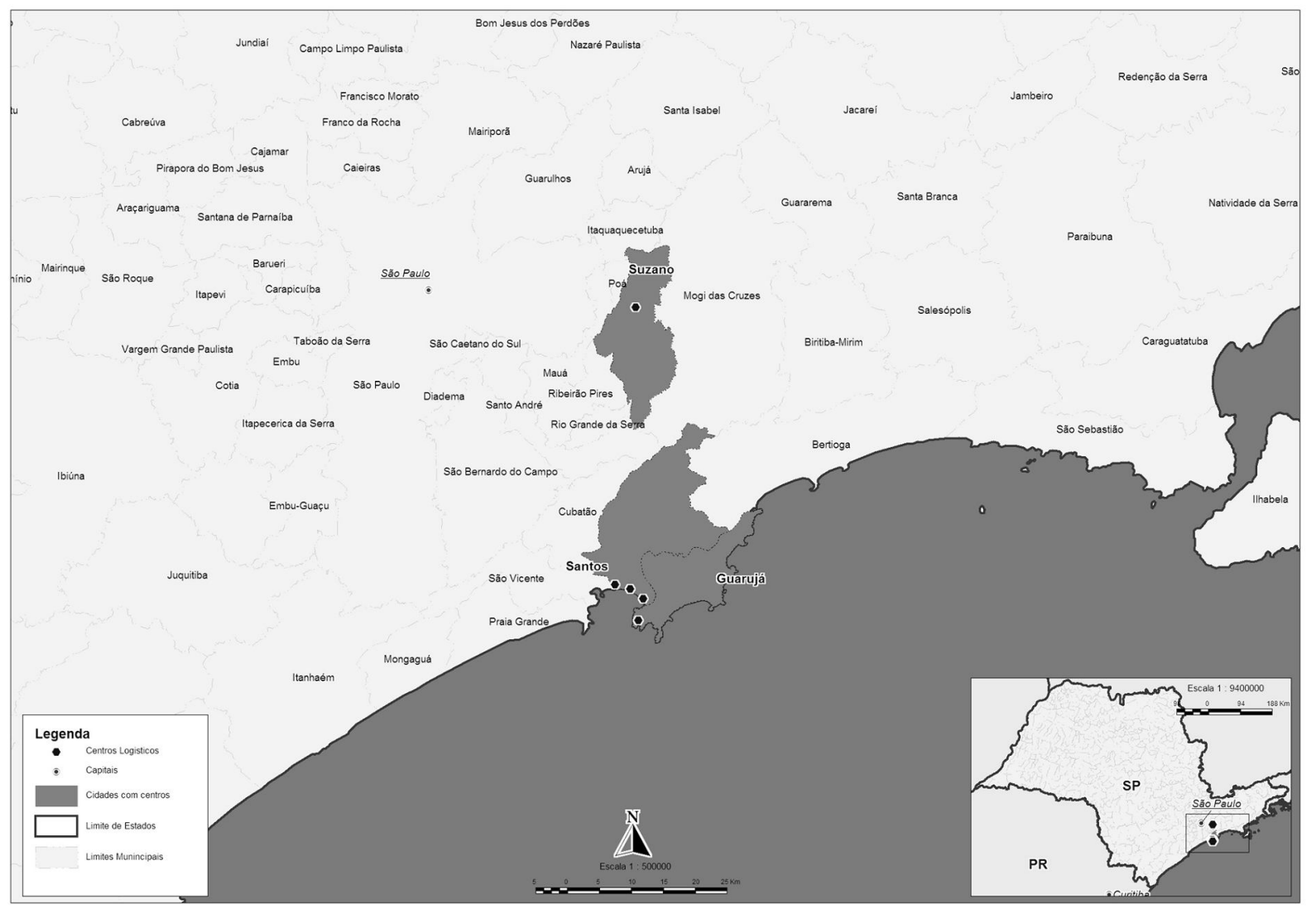

Elaboração própria baseada nos dados da Secretaria da Receita Federal (2009)

de grandes empresas exportadoras e importadoras. Desse modo, a maioria dos armazéns que hoje são CLIAs já existiam desde a década de 1980, e portanto, as lógicas de suas localizações responderam a fatores existentes naquele período.

Os quatro CLIAs que se localizam nas margens do porto de Santos ali estão porque atuavam antigamente como Terminais RetroPortuários e foram sendo alfandegados e transformados em Estações Aduaneiras do Interior e CLIAs. Como são parte de grandes empresas do mercado de armazéns gerais, tendo na zona portuária seu foco de atividades, esses CLIAs são formas geográficas (SANTOS, 1978) que atravessaram décadas adaptandose a novas atribuições exigidas pelo aumento constante dos fluxos internacionais de mercadoria. Portanto, após surgirem como terminais retroportuários, foram alfandegados e, sucessivamente, fizeram parte do processo de interiorização das aduanas (PENHA, 2005) quando passaram a funcionar como EADIs e, agora, transformaram-se em CLIAs.

Essa sucessão de transformações dos recintos em questão nos deixa claro que suas 
instalações se mantiveram nos mesmos locais onde surgiram - cerca de três décadas atrás entretanto, seus atributos e funções foram se modificando ao longo do tempo. Estão concentrados na área portuária de Santos porque ela representa uma especialização territorial produtiva (SANTOS e SILVEIRA, 2001) desde o século XIX e, como tal, recebeu ao longo do tempo vetores de modernizações densidades técnicas e normativas - no sentido de aumentar essa especialização. Os CLIAs são elementos que, somados a uma infinidade de outros, dotam os arredores do porto de Santos de uma especialização nos procedimentos de movimentação, armazenamento, despacho e logística, suficientes para sua autorreprodução e seu aprofundamento.

O CLIA presente em Suzano também tem sua localização explicada por processos presentes já no início do período técnicocientífico e informacional. Atuando como armazém de cargas, já na década de 1970, teve, como os outros, passagens gradativas até sua transformação em CLIA. Pôde operar como Depósito Alfandegado Público, depois como Estação Aduaneira do Interior e, agora, é CLIA. A empresa que o administra, CRAGEA, desde o início de suas atividades sempre teve como clientes grandes indústrias do ABC paulista, região metropolitana de São Paulo e Vale do Paraíba, o que explica sua localização.

Como já dito, os verdadeiros motivos da criação dos CLIAs e, mais especificamente, o fato de serem estes cinco os estabelecimentos que receberam as licenças oficiais por parte da Receita Federal, são de difícil percepção, pois confundem fatores políticos e econômicos. Os fatores econômicos são os mais claros e explícitos e podem ser sintetizados no esforço de liberalização do mercado de recintos alfandegados no intuito de responder prontamente ao aumento da demanda dos serviços especializados de despacho aduaneiro dos últimos anos. Inclusive, estes foram os motivos alegados no documento de Exposição de Motivos para a MP 320. Entretanto, existem os fatores políticos, sempre mais dissimulados, mas de alguma forma apreendidos.

As empresas Deicmar S/A ${ }^{11}$ e CRAGEA, concessionárias de portos secos antes da passagem ao regime de CLIA, tinham contratos de concessão na iminência de término logo no momento da proposta de criação dos CLIAs. A medida provisória 320 só conseguiu sair por meio da pressão política dessas duas grandes empresas somada àquela das outras duas (Armazéns Gerais Columbia e Grupo Mesquita). Não é a toa que apenas esses grandes grupos do mercado de armazéns gerais conseguiram a licença para operar como CLIAs. Entendemos, então, que a criação dos CLIAs e a localização atual deles respondem a fatores econômicos claros e fatores políticos parcialmente esclarecidos.

Apesar do arquivamento da medida provisória em dezembro de 2006, o debate sobre a liberalização do setor, isto é, a flexibilização do modelo jurídico de criação de novas estações aduaneiras em zona secundária, está em pleno movimento, seja entre as empresas de armazéns gerais e suas associações representativas, seja entre estas e seus representantes políticos nas diversas instâncias do poder público. Desse modo, vivemos ainda um período de adequação do território, sobretudo em seu sistema de aduanas, aos crescentes fluxos de mercadorias internacionais, e a medida provisória 320 é apenas mais uma mostra deste movimento.

\section{Notas}

${ }^{1}$ François Chesnais (1996), em seus estudos sobre a mundialização do capital, aponta como consequência direta do aumento dos Investimentos Externos Diretos (IED) o aumento do fluxo internacional de mercadorias entre estabelecimentos de uma mesma multinacional, isto é, exportações e importações realizadas entre filiais localizadas em países diferentes. 
2 De acordo com o Decreto-Lei no 37 de 1966: Zona primária - compreendendo as faixas internas de portos e aeroportos, recintos alfandegados e locais habilitados nas fronteiras terrestres, bem como outras áreas nos quais se efetuem operações de carga e descarga de mercadoria, ou embarque e desembarque de passageiros, procedentes do exterior ou a ele destinados; Zona secundária - compreendendo a parte restante do território nacional, nela incluídos as águas territoriais e o espaço aéreo correspondente.

${ }^{3}$ Exposição de Motivos (EM) nº 00158/2005.

4 O despacho aduaneiro de mercadorias é o procedimento mediante o qual é verificada a exatidão dos dados declarados pelo importador/ exportador em relação às mercadorias importadas/exportadas, aos documentos apresentados e à legislação específica, com vistas ao seu desembaraço aduaneiro Secretaria da Receita Federal.

${ }^{5}$ Necessário para o transporte de mercadorias importadas ou despachadas à exportação entre dois recintos alfandegados, realizado por empresa habilitada pela Receita Federal.

${ }^{6}$ Estabelecido com o Decreto $n^{\circ} 1.910$, de 21 de maio de 1996 , já para os portos secos.
7 Estabelecido pela Instrução Normativa SRF n 79/ 2001 para zona primária e secundária.

8 O Decreto $n^{\circ} 1.910$, de 21 de maio de 1996, normatiza as atividades realizadas por Estações Aduaneiras do Interior (EADI).

${ }^{9}$ Medida provisória n 320, de 24 de agosto de 2006. Dispõe sobre a movimentação e armazenagem de mercadorias importadas ou despachadas para exportação, o alfandegamento de locais e recintos, a licença para explorar serviços de movimentação e armazenagem de mercadorias em Centro Logístico e Industrial Aduaneiro, altera a legislação aduaneira e dá outras providências.

10 O aglomerado metropolitano é uma regionalização feita por Sandra Lencioni (2003) que abrange a Região Metropolitana de São Paulo e seu entorno, num raio de aproximadamente $250 \mathrm{~km}$.

${ }^{11} \mathrm{Na}$ data de 13 de dezembro de 2006, o jornal "Folha de S. Paulo" publicou artigo que revelou a doação de $\mathrm{R} \$ 10.000$ por parte da empresa Deicmar S/A à campanha eleitoral de Lula, prática ilegal para empresas concessionárias de serviços públicos, sugerindo troca de favores entre a empresa e o novo governo.

\section{Bibliografia}

ARROYO, Mónica. Território nacional e mercado externo. Uma leitura do Brasil na virada do século $X X$. Tese de Doutorado. Departamento de Geografia, FFLCH, USP, 2001.

. "São Paulo e os fluxos internacionais de mercadorias: a espessura de uma região metropolitana", in: CARLOS, Ana Fani e OLIVEIRA, Ariovaldo U. (Orgs.), Geografias de São Paulo. A metrópole do século XXI. São Paulo: Contexto, 2004.

CHESNAIS, François. A mundialização do capital. São Paulo: Xamã, 1996.

HARVEY, David. Condição pós-moderna. São Paulo: Edições Loyola, 2004.
LENCIONI, Sandra. "Cisão territorial da indústria e integração regional no Estado de São Paulo", in: GONÇALVES, M. F., BRANDÃO, C. A. e GALVÃO, A. C. F. (Orgs.), Regiões e cidades, cidades nas regiões. Editora Unesp, 2003.

PACCHIEGA, Rafael. Produtividade Espacial e Comércio Exterior: O Papel das Estações Aduaneiras de Interior na Cidade de São Paulo. Trabalho de Graduação Individual. Departamento de Geografia, FFLCH, USP, 2009

PENHA, Lucas. Interiorização das aduanas e competitividade territorial no Brasil: tipologia e topologia das estações aduaneiras do interior. Monografia de conclusão de curso. Universidade Estadual de Campinas, Departamento de Geografia, 2005. 
RAFFESTIN, Claude. Por uma geografia do poder. São Paulo: Ática, 1993.

SANTOS, Milton. Por uma geografia nova. São Paulo: Hucitec, 1978.

O espaço dividido: os dois circuitos da economia urbana de países subdesenvolvidos. Rio de Janeiro: Francisco Alves, 1979.

. "O retorno do território", in: SANTOS, M., SOUZA, M. Adélia A. e SILVEIRA, M. Laura (orgs.), Território: Globalização e Fragmentação. São Paulo: Hucitec, 1994.
SANTOS, Milton. Por uma outra globalização. Rio de Janeiro: Record, 2001. 2002.

. A natureza do espaço. São Paulo: Edusp,

SANTOS, Milton e SILVEIRA, M. Laura. O Brasil: território e sociedade no início do século XXI. Rio de Janeiro: Record, 2001.

SILVEIRA, María Laura. "A região e a invenção da viabilidade do território", in: SOUZA, M. Adélia S. (Org.), Território brasileiro: usos e abusos. Campinas: Edições Territorial, 2003.

Trabalho enviado em outubro de 2009

Trabalho aceito em dezembro de 2009 